\title{
A variação estilística em diferentes situações de leitura: variedade capixaba
}

\author{
The style variation in different reading situations: Capixaba variety \\ Irma Iunes Miranda \\ Lilian Coutinho Yacovenco \\ Leila Maria Tesch \\ Alexsandro Rodrigues Meireles \\ Universidade Federal do Espírito Santo - Vitória - Espírito Santo - Brasil
}

\begin{abstract}
Resumo: O estilo, juntamente com os recursos linguísticos e sociais, integra os estudos da variação sociolinguística. Com base na proposta de W. Labov, que tem como foco da variação estilística a atenção que o sujeito presta à própria fala, esta pesquisa tem o objetivo de observar se ocorrem diferenças estilísticas entre as leituras de sequência de frases (do tipo "Digo palavra baixinho") e de um texto (do tipo conto infantil). Os parâmetros observados para tais propósitos são as frequências dos dois primeiros formantes (F1 e F2) de vogais tônicas e pré-tônicas, a duração dessas vogais (Dur) e a ênfase espectral (SE). O resultado confirmou que estilos distintos promovem diferentes reações nos leitores: a leitura de frases descontextualizadas produziu uma fala mais atenta e com traços de formalidade e a leitura do texto, que favoreceu um maior envolvimento do leitor, produziu um estilo mais casual.
\end{abstract}

Palavras-chave: Estilo; Análise acústica; Sistema vocálico; Português brasileiro; Dialeto capixaba

\begin{abstract}
The style, along with linguistic and social resources, integrates the study of sociolinguistic variation. Based on W. Labov perspective, who mainly focused on the attention that the speaker pays to his/her own speech when he analysed stylistic variation, this research aims to observe possible stylistic differences between sentence reading (type "Digo palavra baixinho") and text reading (type children's tale). The parameters analysed for such purposes are the frequencies of the first an second formants (F1 and F2) of stressed and pre-stressed vowels, the duration of those vowels (Dur) and their spectral emphasis (SE). The result confirmed that different styles promote different reactions in readers: the decontextualized sentences reading produced a more monitored speach than the text reading.
\end{abstract}

Keywords: Style; Acoustic analysis; Vowel system; Brazilian Portuguese; Capixaba dialect

\section{Introdução}

A Teoria da Variação e Mudança Linguística (LABOV, 2008 [1972]) tem por objetivo "o estudo da estrutura e da evolução da língua dentro do contexto social da comunidade de fala. (...) [A preocupação do estudo sociolinguístico são] as formas das regras linguísticas, sua combinação em sistemas, a coexistência de vários sistemas e a evolução destas regras e sistemas com o tempo" (LABOV, 2008 [1972], p. 216). É certo que os estudos sociolinguísticos se concentram na relação entre língua e sociedade, ou melhor, na influência de fatores sociais (idade, sexo/gênero, classe social, região do falante) sobre os fenômenos linguísticos. A preocupação com o estilo, abordada por Labov desde seu estudo sobre a fala de Nova York, não tem sido o centro de interesse da Sociolinguística Variacionista. Entretanto, o estilo, paulatinamente, vem ocupando um lugar de destaque nos estudos variacionistas, seja sob a visão de Labov, de A. Bell ou de outros estudiosos. Portanto, o estudo da variação sociolinguística tem o estilo como um de seus componentes, que juntamente com os recursos internos (linguísticos) e os recursos sociais formam as vias mais tradicionais dos estudos sociolinguísticos.

A noção de estilo vem se modificando, conforme evoluem os estudos sociolinguísticos. Vários autores 
discutem o que é estilo e qual sua importância para os estudos linguísticos. W. Labov (2006) entende a variação estilística como um meio de se observarem as mudanças linguísticas em curso, levando sempre em conta a atenção que o falante dá a sua própria fala. A. Bell (2005) questiona o referencial utilizado por Labov e credita à audiência a mudança de estilo exibida pelo falante no momento comunicativo (audience design). Finegan e Biber (2005) entendem que a situação de fala se mostra como o ponto chave para a explicação do complexo fenômeno da variação de estilo. Coupland (2005) defende um ponto de vista ainda mais amplo, que não restringe o estudo do estilo a um único foco, estendendo sua análise para além da relação do falante com seu lugar social e levando em conta a identidade (self) desse falante.

A teoria envolvida nessa pesquisa assume W. Labov como principal referência, reconhecendo como foco da variação estilística a atenção que o sujeito presta à sua própria fala. Este trabalho, que é parte da tese de doutorado intitulada Análise Acústica das Vogais Orais Tônicas e Pré-Tônicas e Sua Coarticulação na Variedade Capixaba, tem por objetivo observar se ocorrem diferenças estilísticas nas leituras de dois diferentes objetos: o primeiro deles é uma sequência de frases do tipo "Digo palavra baixinho" e o segundo é um texto do tipo conto infantil. Os parâmetros observados para tais propósitos são as frequências dos dois primeiros formantes (F1 e F2) de vogais tônicas e pré-tônicas, a duração dessas vogais (Dur) e a ênfase espectral (SE). O que se espera dessa análise é que os objetos distintos promovam diferentes reações nos leitores de modo que a leitura da sequência de frases (por serem descontextualizadas) produza uma fala mais atenta e com traços de formalidade, diferentemente da leitura do conto de fadas que favorece um maior envolvimento do leitor levando-o a produzir uma fala menos monitorada e consequentemente de um estilo mais casual.

\section{Parâmetros Acústicos Analisados}

\subsection{Frequências dos formantes - F1 E F2}

Os formantes são reconhecidos como os principais correlatos acústicos associados à qualidade de uma vogal, juntamente com a duração. As frequências dos dois primeiros formantes são suficientes para identificação da qualidade acústica do repertório vocálico do português brasileiro. Assim, o diagrama bidimensional, que utiliza as frequências dos formantes $(\mathrm{F} 1 \times \mathrm{F} 2)$, é o esquema mais utilizado para a representação acústica dos sons vocálicos.

$\mathrm{O}$ valor da frequência do primeiro formante $(\mathrm{F} 1)$ possui uma relação inversamente proporcional à posição vertical da língua no momento da produção da vogal, ou seja, quanto mais alta a vogal, ou, em outras palavras, quanto maior a constrição da passagem de ar, menor o valor da frequência de F1. Assim, as vogais altas [i] e $[\mathrm{u}]$ apresentam valores de frequência de $\mathrm{F} 1$ menores se comparados às das vogais baixas [a] e [æ] (CLARK; YALLOP; FLETCHER, 2007).

Para F2, os valores de frequência estão relacionados com a posição ântero-posterior do corpo da língua. Quanto mais posterior for a vogal, menor o valor da frequência de F2, portanto, as vogais anteriores [i] e [e] possuem valores de frequência de F2 maiores que os das vogais posteriores [u] e [o] (CLARK; YALLOP; FLETCHER, 2007).

Estabelece-se, assim, uma correspondência acústicoarticulatória que permite a identificação das vogais através do gráfico bidimensional $\mathrm{F} 1 \mathrm{xF}$, cujo eixo vertical abriga os valores de F1 indicando a altura da voga/língua e o eixo horizontal, os valores de F2 indicando o avanço da vogal/língua (KENT; READ, 1992).

\subsection{Duração - Dur}

A duração de uma vogal está diretamente relacionada com o ritmo e a taxa de elocução do falante, o grau de tonicidade, a posição de proeminência por ela ocupada na frase. Esse parâmetro traz informações que contribuem para uma análise mais precisa dos padrões e processos que estruturam o discurso e suas alterações. Assim, a duração de um segmento apresenta uma relação bastante íntima com o estilo no qual o sujeito se encontra incluído no momento da fala. Sua emoção, seu estado físico e psicológico entre outros fatores são influências determinantes para a elocução desenvolvida no ato de fala.

A duração de uma vogal no português não tem função distintiva, mas varia, entre muitos fatores, com o grau de tonicidade. De acordo Barbosa, Eriksson e Ákesson (2013) em seu estudo sobre três correlatos acústicos (F0, duração e ênfase espectral) em três diferentes estilos de fala no português brasileiro, as vogais são mais longas e variam mais em duração em posições de maior tonicidade independentemente do estilo ou do gênero do falante.

\section{3 Ênfase espectral - SE}

Sluijter e van Heuven (1996) mostraram que, quando se trata de tonicidade, as diferenças de intensidade em regiões de altas frequências apresentam maior influência do esforço fisiológico do que as variações das frequências em região mais baixa. Na fala natural as sílabas tônicas são produzidas com maior esforço vocal e o equilíbrio espectral, isto é, segundo Sluijter e van Heuven (1996) a relação entre energias espectrais apresenta-se como um parâmetro forte e confiável para a análise da tonicidade. 
Assim, vogais que ocupam posições proeminentes em termos prosódicos tendem a ser produzidas com maior esforço vocal do que aquelas que ocupam posições não proeminentes. Essa tendência faz com que a distribuição de energia ao longo do espectro seja mais intensa nas faixas de mais alta frequência. A ênfase espectral, termo correlato ao de equilíbrio espectral, conforme definida por Traunmüller e Eriksson (1995), comporta-se como um correlato acústico do esforço vocal: quanto maior o esforço vocal, maior a energia nas altas frequências em relação à da região em torno da frequência fundamental e, consequentemente, maior a ênfase espectral. No caso de um estilo resultante de fala monitorada, o que se espera é o emprego de um maior esforço vocal e, por conseguinte, maiores valores de ênfase espectral devem ser observados.

\section{Método}

\subsection{Corpus}

O corpus utilizado neste trabalho é o mesmo levantado para a tese de doutorado de Miranda (2017), que investiga acusticamente as vogais pré-tônicas e tônicas da variedade capixaba (Vitória e Vila Velha-ES).

As gravações ocorreram em duas etapas. A primeira consistiu de gravações de frases-veículo do tipo "Digo palavra baixinho". Sabe-se que esse estilo não promove uma leitura rápida, pois o sujeito precisa pausar entre frases, além de não conhecer a sequência utilizada durante a gravação. Ocorre, assim, uma tendência de abandono da coloquialidade e de maior monitoramento da fala.

As palavras registradas possuíam estrutura do tipo CV1'CV2CV3. Esse grupo de palavras foi composto por 105 itens diferentes (Anexo I), todos paroxítonos, em que V2 assumisse as sete possibilidades de tônicas /i, e, $\varepsilon$, a, ə, o, u/, V1 apresentasse as cinco possíveis condições para pré-tônicas (/i, e, a, o, u/), e V3, e, para a pós-tônica final, as vogais [I], [e] e [于]. Assim, com sete tônicas, cinco pré-tônicas e três pós-tônicas finais tem-se um conjunto de $105(7 \times 5 \times 3)$ palavras trissílabas. Nas posições em que não foi possível encontrar vocábulos que atendessem às combinações acima especificadas, o uso de logatomas se fez necessário, sendo esses considerados como palavras não familiares, aparecendo sempre entre aspas.

Alguns critérios nortearam a escolha das palavras de formação do corpus. Um deles é o da familiaridade, que foi escolhido em detrimento do critério de frequência por esse depender do corpus enquanto a familiaridade depende do falante. Muitos vocábulos, embora pouco frequentes em análises de corpus, são bastante familiares para a maioria dos falantes do português brasileiro, como caneca e pisada, que, no Banco de Português da PUC-SP (BERBER SARDINHA, 2010), aparecem com frequência relativamente baixa e, no entanto, tendem a ser classificadas como familiares.

A segunda etapa de gravação teve como objetivo a análise das mesmas vogais nas mesmas palavras-chave das sentenças isoladas (nem todas as palavras foram utilizadas), porém inseridas em um texto redigido de maneira coloquial. Com o objetivo de encorajar um estilo de leitura mais informal, foi solicitada aos participantes uma leitura prévia do texto para que ficassem familiarizados com o tema, promovendo, assim, uma leitura fluente. O texto utilizado para esse fim trata-se de uma releitura da fábula $A$ Cigarra e a Formiga, de autoria atribuída a Esopo, que foi recontada por Jean de La Fontaine. O texto entregue para leitura não contou com palavras em destaque para que a leitura pudesse fluir naturalmente, sem interferências. Foi pedido aos participantes que a leitura fosse feita da maneira mais natural possível, como se a história estivesse sendo contada para uma criança.

Os dados são resultantes de análises dos parâmetros F1, F2, Dur e SE das vogais pré-tônicas e tônicas das palavras investigadas, ora inseridas nas frases, ora no texto. As análises desses parâmetros foram realizadas com o auxílio do script Computing Vowel Parameters para o programa Praat ( $<$ www.praat.org $>$ ), desenvolvido por Barbosa (2015) para o Projeto Temático "Fronteiras e Assimetrias em Fonética e Fonologia".

Conforme anteriormente explicitado, F1 e F2 dão conta de identificar a natureza das vogais e revelar suas características no que se refere à articulação, sendo F1 relacionado à altura e F2, ao grau de anterioridade (eixo horizontal) em que a vogal é produzida. O parâmetro duração (Dur) está fortemente vinculado à produção prosódica, incluindo contraste entre tônicas e átonas referindo-se ao tempo de produção acústica da vogal. A ênfase espectral (SE) é um correlato acústico do esforço vocal: quanto maior o esforço vocal, maior a energia nas altas frequências em relação à da região em torno da fundamental e, consequentemente, maior a ênfase espectral.

De acordo com Fant (apud LIEBERMAN e BLUMSTEIN, 1988, p. 166), os padrões de frequências dos formantes, para cada vogal em particular, são determinados pelo formato e tamanho do trato supralaríngeo. Assim, para compensar as distinções fisiológicas entre indivíduos é necessário que se submetam os dados de frequências ao método matemático da normalização, que corrige o efeito de distinções fisiológicas entre indivíduos sem alterar suas características sociolinguísticas. Assim, todos os dados passaram por um processo de normalização (método de Lobanov) para possibilitar a comparação das frequências produzidas por diferentes sujeitos. Além da normalização, os dados foram tratados estatisticamente por meio do teste $\mathrm{T}$ (Student) com nível de significância de $5 \%(\alpha=0,05)$. 


\subsection{Informantes}

Os dados foram extraídos de gravações realizadas com falantes capixabas, nascidos, criados e moradores das cidades de Vitória e Vila Velha (ES). Dez falantes participaram das gravações, sendo cinco, masculinos e cinco, femininos, todos pertencentes à faixa etária de vinte a cinquenta anos, graduados ou com graduação em curso.

Para que houvesse um controle que propiciasse uma homogeneidade da amostra, os falantes forneceram informações pertinentes por meio de um questionário que visa a garantir o cumprimento dos critérios básicos de seleção dos falantes.

\section{Análise dos dados - comparando os estilos "leitura de frases" (FRASES) com "leitura de texto" (TEXTO)}

Na comparação entre os estilos FRASES e TEXTO, o que se espera, assumindo a visão de W. Labov, é que os parâmetros analisados apontem para uma maior formalidade no primeiro estilo, já que as frases lidas, do tipo "Digo palavra baixinho", estão isoladas de qualquer contexto, o que pode levar o sujeito a manter certo grau de hiper-articulação em sua fala. Já o texto lido, $A$ Cigarra e a Formiga, difere das frases por apresentar um contexto ao leitor que, familiarizado com a história, tende a desenvolver uma leitura mais livre, menos monitorada, hipoarticulada.

Segue, abaixo, o resultado da comparação entre FRASES e TEXTO após a realização do teste T dos dados normalizados para (A) PRÉ-TÔNICAS DE CONTROLE, ou seja, aquelas seguidas de tônicas de mesma qualidade como na palavra visito; (B) PRÉ-TÔNICAS DE TESTE, aquelas seguidas de tônicas de qualidades diferentes como em tapete e, finalmente, (C) TÔNICAS.

Para as Tabelas 1 a 7 , que trazem os resultados das análises estatísticas das comparações entre situações FRASES (F) e TEXTO (T), os seguintes símbolos serão utilizados:

$[<]$ para significância menor que $5 \%$, sendo a média do parâmetro para $\mathrm{F}$ menor que a média do parâmetro para T;

[>] para significância menor que 5\%, sendo a média do parâmetro para $\mathrm{F}$ maior que a média do parâmetro para $\mathrm{T}$;

[=] para significância maior ou igual à $5 \%$ em que não foi significativa a diferença entre as médias do parâmetro para $\mathrm{F}$ e $\mathrm{T}$.

\section{(A) PRÉ-TÔNICAS CONTROLE}

As pré-tônicas controle são aquelas que precedem tônicas de mesma qualidade, não ocorrendo assim influência da tônica no sentido de alterar seus parâmetros de qualidade F1 e F2. Exemplo: birita, beleza, parada, socorro, cutuque.

A Tabela 1 traz os resultados do teste $\mathrm{T}$ que compara as pré-tônicas controle de FRASES (F) e TEXTO (T) no que tange os parâmetros F1, F2, Dur e SE.

Tabela 1. Pré-tônicas de controle - Teste $T(a=0,05)$

\begin{tabular}{ccccc}
\hline Pré-tônica - exemplo & F1 & F2 & Duração & SE \\
\hline li/ - visite & $=$ & $=$ & $=$ & $=$ \\
le/ - beleza & $\mathrm{F}>\mathrm{T}$ & $=$ & $=$ & $=$ \\
/a/ - parada & $\mathrm{F}>\mathrm{T}$ & $\mathrm{F}>\mathrm{T}$ & $=$ & $=$ \\
/o/ - socorra & $=$ & $=$ & $=$ & $=$ \\
/ $\mathrm{u}$ - futura & $\mathrm{F}>\mathrm{T}$ & $=$ & $\mathrm{F}>\mathrm{T}$ & $=$ \\
\hline
\end{tabular}

Na Tabela 1, pode-se observar o comportamento das pré-tônicas controle:

- Diante da tônica /i/, não há diferenças significativas.

- Diante da tônica /e/, são mais baixas em FRASES.

- Diante da tônica/a/, são mais baixas e mais anteriores em FRASES.

- Diante da tônica /o/, não há diferenças significativas.

- Diante da tônica /u/, são mais baixas e com maior duração em FRASES.

- Para TEXTO, as vogais /e/, /a/, /u/ tornam-se ligeiramente mais altas. Todas as vogais tendem a tornar-se mais posteriores. A vogal /a/ tende a valores centrais no que diz respeito à altura $(\mathrm{F} 1)$.

- Os parâmetros não citados não apresentam diferenças significativas na comparação FRASES e TEXTO.

$\mathrm{O}$ comportamento das vogais quanto à qualidade, que foi descrito acima, é melhor observado na Figura 1 $(\mathrm{F} 1 \times \mathrm{F} 2)$.

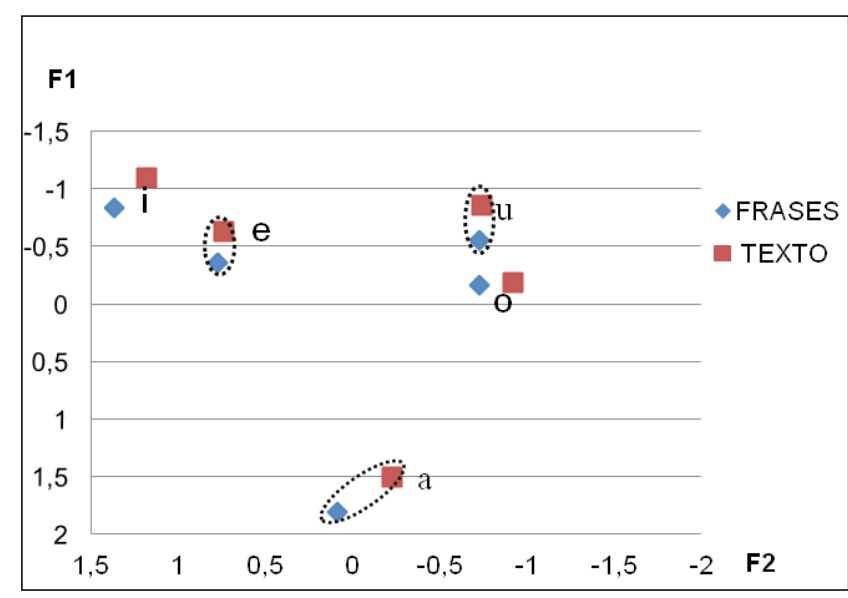

Figura 1. Pré-tônicas Controle FRASES x TEXTO (F1×F2) 


\section{(B) PRÉ-TÔNICAS TESTE}

As pré-tônicas de teste, diferentemente das de controle, são aquelas que apresentam tônicas de qualidades diferentes. Nas tabelas apresentadas abaixo constam os resultados dos testes T comparando FRASES (F) e TEXTO (T) para as diferentes situações de tônicas.

\section{(B.1) PRÉ-TÔNICA TESTE /i/}

Tabela 2. Pré-tônica Teste /i/ - Teste $T(a=0,05)$

\begin{tabular}{ccccc}
\hline Tônica - exemplo & F1 & F2 & Duração & SE \\
\hline le/ - pipeta & Isufic. & Isufic. & Isufic. & Isufic. \\
/E/-pivete & $=$ & $\mathrm{F}>\mathrm{T}$ & $\mathrm{F}>\mathrm{T}$ & $=$ \\
/a/ - pitada & $=$ & $=$ & $\mathrm{F}>\mathrm{T}$ & $\mathrm{F}>\mathrm{T}$ \\
/ $\mathrm{J} /$ - filhote & $=$ & $\mathrm{F}>\mathrm{T}$ & $=$ & $=$ \\
/0/ - Tinoco & $=$ & $\mathrm{F}>\mathrm{T}$ & $=$ & $=$ \\
/u/ - minuto & $\mathrm{F}<\mathrm{T}$ & $\mathrm{F}>\mathrm{T}$ & $=$ & $=$ \\
\hline
\end{tabular}

- Diante da tônica /e/, os dados foram insuficientes por não haver no texto palavra que preenchesse o requisito.

- Diante da tônica $/ \varepsilon /$, é mais anterior e de maior duração em FRASES.

- Diante da tônica /a/, apresenta maior duração e SE em FRASES.

- Diante da tônica /っ/, é mais anterior em FRASES.

- Diante da tônica /o/, é mais anterior em FRASES.

- Diante da tônica /u/, é mais alta mais anterior em FRASES.

- A vogal pré-tônica teste /i/ confirma a tendência observada na pré-tônica controle que é a de se tornar mais baixa e mais posterior no estilo TEXTO.

- A influência das vogais tônicas na realização da pré-tônica /i/ também fica bastante perceptível

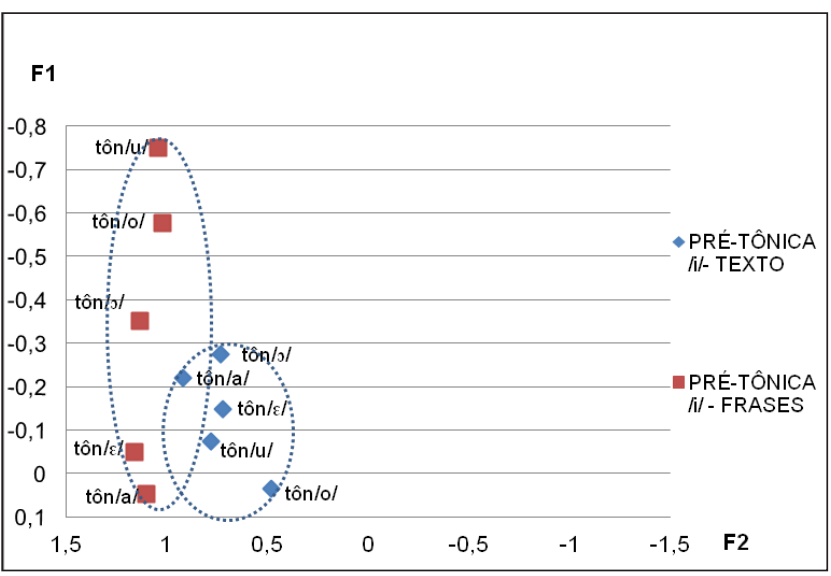

Figura 2. Pré-tônica Teste /i/ - FRASES × TEXTO $(F 1 \times F 2)$ na Figura 2, principalmente no que diz respeito à altura (F1). Quanto mais alta a tônica, mais alta também é a realização da pré-tônica teste /i/. No entanto, não há diferenças significativas para F1 entre estilos, com exceção para a tônica /u/. Esse comportamento deixa clara a influência da tônica na qualidade da pré-tônica.

O comportamento da pré-tônica teste /i/ diante das diversas tônicas, no que se refere à qualidade, está ilustrado na Figura $2(\mathrm{~F} 1 \times \mathrm{F} 2)$.

\section{(B.2) PRÉ-TÔNICA TESTE /e/}

Tabela 3. Pré-tônica Teste /e/ - Teste $T(\alpha=0,05)$

\begin{tabular}{|c|c|c|c|c|}
\hline Tônica - exemplo & F1 & F2 & Duração & SE \\
\hline /i/ - decide & $=$ & $=$ & $\mathrm{F}>\mathrm{T}$ & $=$ \\
\hline$|\varepsilon|-$ peteca & $=$ & $\mathrm{F}>\mathrm{T}$ & $=$ & $=$ \\
\hline lal-metade & $=$ & $=$ & $=$ & $=$ \\
\hline lo/-decora & $=$ & $\mathrm{F}>\mathrm{T}$ & $F>T$ & $\mathrm{~F}>\mathrm{T}$ \\
\hline /o/ - remova & $=$ & $\mathrm{F}>\mathrm{T}$ & $F>T$ & $\mathrm{~F}>\mathrm{T}$ \\
\hline$/ \mathrm{u} /$ - peluda & $=$ & $\mathrm{F}>\mathrm{T}$ & $=$ & $=$ \\
\hline
\end{tabular}

- Diante da tônica /i/, apresenta duração maior em FRASES e demais fatores sem diferenças significativas.

- Diante da tônica $/ \varepsilon /$, é mais anterior em FRASES e demais fatores sem diferenças significativas.

- Diante da tônica /a/, não apresenta diferenças significativas para os parâmetros analisados.

- Diante da tônica /o/, é mais anterior, apresenta maior duração e maior SE em FRASES.

- Diante da tônica /o/, é mais anterior, apresenta maior duração e maior SE em FRASES.

- Diante da tônica /u/, é mais anterior em FRASES e demais fatores sem diferenças significativas.

- A influência das vogais tônicas na realização da pré-tônica /e/ em FRASES fica bastante perceptível principalmente no que diz respeito à altura (F1). Quanto mais alta a tônica, mais alta também é a realização da pré-tônica teste /e/. Não ocorrem diferenças significativas para F1 entre estilos.

- O parâmetro F2 apresenta distinção entre estilos, fazendo com que a vogal /e/ se apresente mais central para $/ \varepsilon /, / \mathrm{o} /, / \mathrm{o} / \mathrm{e} / \mathrm{u} / \mathrm{em}$ TEXTO. Assim, a pré-tônica /e/ apresenta um comportamento mais canônico em FRASES.

O comportamento da pré-tônica teste /e/ diante das diversas tônicas, no que se refere à qualidade, está ilustrado na Figura $3(\mathrm{~F} 1 \times \mathrm{F} 2)$. 


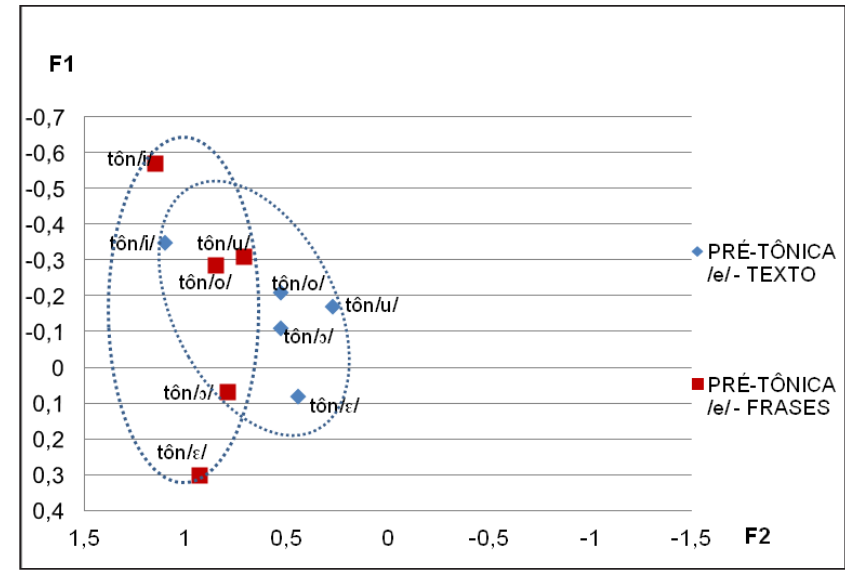

Figura 3. Pré-tônica Teste /e/ - FRASES × TEXTO $(F 1 \times F 2)$

\section{(B.3) PRÉ-TÔNICA TESTE /a/}

Tabela 4. Pré-tônica Teste /a/ - Teste $T(a=0,05)$

\begin{tabular}{ccccc}
\hline Tônica- exemplo & F1 & F2 & Duração & SE \\
\hline /i/ - cabide & $=$ & $\mathrm{F}>\mathrm{T}$ & $=$ & $=$ \\
/e/ - tapete & $=$ & $=$ & $=$ & $=$ \\
$/ \varepsilon /$ - pateta & $=$ & $\mathrm{F}>\mathrm{T}$ & $=$ & $=$ \\
$/ \mathrm{o} /$ - pacote & $\mathrm{F}>\mathrm{T}$ & $\mathrm{F}>\mathrm{T}$ & $=$ & $=$ \\
$/ \mathrm{o} /$ - barroco & $\mathrm{F}>\mathrm{T}$ & $\mathrm{F}>\mathrm{T}$ & $=$ & $=$ \\
$/ \mathrm{u} /$ - papuda & $=$ & $\mathrm{F}>\mathrm{T}$ & $=$ & $=$ \\
\hline
\end{tabular}

- Diante da tônica /i/, mais anterior em FRASES e demais fatores sem diferenças significativas.

- Diante da tônica /e/, não apresenta diferenças significativas para os parâmetros analisados.

- Diante da tônica $/ \varepsilon /$, mais anterior em FRASES e demais fatores sem diferenças significativas.

- Diante da tônica /o/, é mais baixa e mais anterior em FRASES e demais fatores sem diferenças significativas.

- Diante da tônica /o/, é mais baixa e mais anterior em FRASES e demais fatores sem diferenças significativas.

- Diante da tônica /u/, mais anterior em FRASES e demais fatores sem diferenças significativas.

- A influência das vogais tônicas na realização da pré-tônica /a/ em FRASES fica bastante perceptível na Figura 4, principalmente no que diz respeito à altura $(\mathrm{F} 1)$. Quanto mais alta a tônica, mais alta é a realização a pré-tônica teste /a/.

- Ocorrem diferenças significativas entre estilos para F1 nas situações de tônicas / / e /o/ que ocupam posições mais altas (centrais) para TEXTO.

- No que diz respeito ao parâmetro F2, a estatística mostra um deslocamento da vogal pré-tônica teste /a/ para uma posição mais posterior em TEXTO.
- A pré-tônica teste /a/ tende a ser mais baixa e anterior em FRASES. A vogal /a/ confirma a tendência observada na Tabela 1 das pré-tônicas de controle.

O comportamento da pré-tônica teste /a/ diante das diversas tônicas, no que se refere à qualidade, está ilustrado na Figura $4(\mathrm{~F} 1 \times \mathrm{F} 2)$.

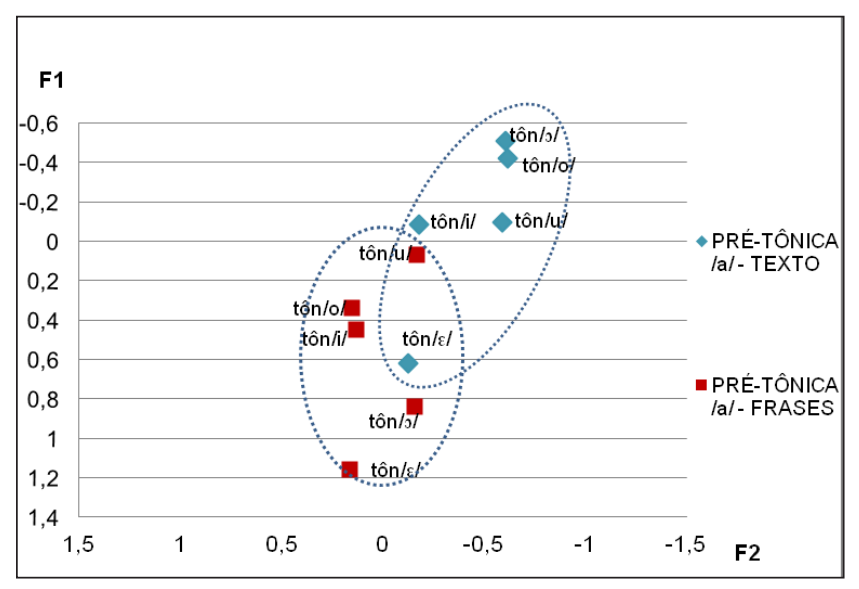

Figura 4. Pré-tônica Teste /a/ - FRASES × TEXTO $(F 1 \times F 2)$

\section{(B.4) PRÉ-TÔNICA TESTE /o/}

Tabela 5. Pré-tônica Teste /o/ - Teste T $(a=0,05)$

\begin{tabular}{ccccc}
\hline Tônica - exemplo & F1 & F2 & Duração & SE \\
\hline li/ - bonita & $\mathrm{F}<\mathrm{T}$ & $\mathrm{F}>\mathrm{T}$ & $\mathrm{F}>\mathrm{T}$ & $\mathrm{F}>\mathrm{T}$ \\
/e/ - cometa & $\mathrm{F}>\mathrm{T}$ & $\mathrm{F}>\mathrm{T}$ & $\mathrm{F}>\mathrm{T}$ & $=$ \\
$/ \varepsilon /$ - boneca & $\mathrm{F}>\mathrm{T}$ & $\mathrm{F}>\mathrm{T}$ & $=$ & $\mathrm{F}>\mathrm{T}$ \\
/a/ - tomate & $\mathrm{F}>\mathrm{T}$ & $\mathrm{F}>\mathrm{T}$ & $=$ & $=$ \\
/ / / bolota & $\mathrm{F}>\mathrm{T}$ & $\mathrm{F}>\mathrm{T}$ & $\mathrm{F}>\mathrm{T}$ & $\mathrm{F}>\mathrm{T}$ \\
/u/ - doçura & $=$ & $\mathrm{F}>\mathrm{T}$ & $=$ & $\mathrm{F}>\mathrm{T}$ \\
\hline
\end{tabular}

- Diante da tônica /i/, mais alta e mais anterior, além de apresentar maior duração e SE em FRASES .

- Diante da tônica /e/, mais baixa e mais anterior e apresenta maior duração em FRASES.

- Diante da tônica $/ \varepsilon /$, mais baixa e mais anterior em FRASES e demais fatores sem diferenças significativas.

- Diante da tônica /a/, é mais baixa e mais anterior em FRASES e demais fatores sem diferenças significativas.

- Diante da tônica / /, é mais baixa e mais anterior com maior duração e SE em FRASES

- Diante da tônica /u/, mais anterior e com maior SE em FRASES e demais fatores sem diferenças significativas.

- Tende a ser mais baixa e anterior em FRASES com exceção de quando diante da tônica /i/. Já a 
pré-tônica de controle /o/ tende a ser mais alta em FRASES.

- A Figura 5 mostra forte influência da qualidade da tônica sobre a realização da pré-tônica teste /o/ em FRASES.

- Em TEXTO, as pré-tônicas apresentam uma redução de duração para /i/, /e/ e / / /, redução da ênfase espectral (SE) para /i/, / / /, / / e /u/ além de apresentar uma nítida redução do espaço ocupado pelas pré-tônicas.

O comportamento da pré-tônica teste /o/ diante das diversas tônicas, no que se refere à qualidade, está ilustrado na Figura $5(\mathrm{~F} 1 \times \mathrm{F} 2)$.

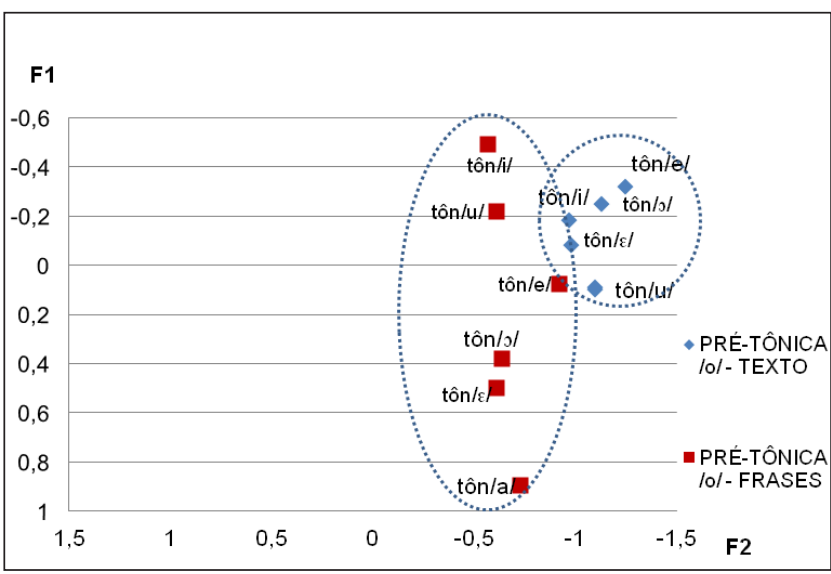

Figura 5. Pré-tônica Teste /o/ - FRASES × TEXTO $(\mathrm{F} 1 \times \mathrm{F} 2)$

\section{(B.5) PRÉ-TÔNICA TESTE /u/}

Tabela 6. Pré-tônica Teste /u/ - Teste $T(a=0,05)$

\begin{tabular}{ccccc}
\hline Tônica - exemplo & F1 & F2 & Duração & SE \\
\hline /i/- buzina & $=$ & $=$ & $\mathrm{F}>\mathrm{T}$ & $=$ \\
/e/-muleta & $=$ & $=$ & $=$ & $=$ \\
/E/- pudera & $=$ & $=$ & $\mathrm{F}>\mathrm{T}$ & $=$ \\
/a/ - furado & $=$ & $=$ & $=$ & $=$ \\
/J/-mucosa & $=$ & $\mathrm{F}>\mathrm{T}$ & $=$ & $=$ \\
/o/- "mutopo" & $\mathrm{F}<\mathrm{T}$ & $=$ & $\mathrm{F}<\mathrm{T}$ & $=$ \\
\hline
\end{tabular}

- Diante da tônica /i/, apresenta duração maior em FRASES e demais parâmetros sem diferenças significativas.

- Diante da tônica /e/, não apresenta diferenças significativas em qualquer dos parâmetros analisados.

- Diante da tônica /\&/, apresenta duração maior em FRASES e demais fatores sem diferenças significativas.
- Diante da tônica /a/, não apresenta diferenças significativas para os fatores analisados.

- Diante da tônica /っ/, é mais anterior em FRASES. Os demais fatores, não apresentam diferenças significativas.

- Diante da tônica /o/, é mais alta e apresenta maior duração em FRASES e demais parâmetros não apresentam diferenças significativas.

- A qualidade da pré-tônica teste /u/ não apresenta fortes distinções entre estilos, com exceção para a altura diante de /o/ que é maior em FRASES bem como a maior anterioridade diante de / /, também em FRASES.

- O estilo TEXTO apresenta forte redução do espaço vocálico.

- Não há distinção significativa entre estilos para SE.

O comportamento da pré-tônica teste / $\mathrm{u} /$ diante das diversas tônicas, no que se refere à qualidade, está ilustrado na Figura $6(\mathrm{~F} 1 \times \mathrm{F} 2)$.

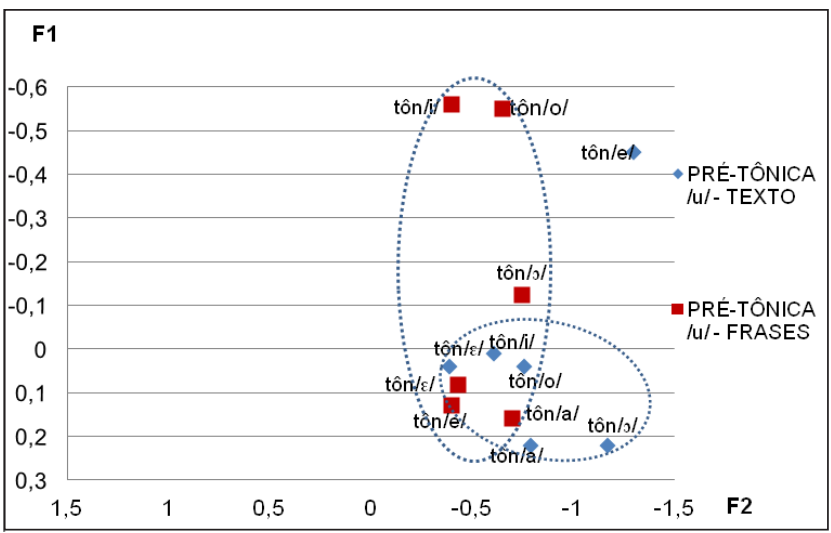

Figura 6. Pré-tônica Teste /u/ - FRASES × TEXTO $(F 1 \times F 2)$

(C) TÔNICAS

Tabela 7. Tônicas - FRASES $\times$ TEXTO - Teste $T(a=0,05$

\begin{tabular}{ccccc}
\hline Tônica & F1 & F2 & Duração & SE \\
\hline$/$ i/ & $\mathrm{F}>\mathrm{T}$ & $\mathrm{F}>\mathrm{T}$ & $=$ & $=$ \\
$/ \mathrm{e} /$ & $\mathrm{F}>\mathrm{T}$ & $=$ & $\mathrm{F}<\mathrm{T}$ & $\mathrm{F}>\mathrm{T}$ \\
$/ \varepsilon /$ & $=$ & $\mathrm{F}>\mathrm{T}$ & $=$ & $=$ \\
$/ \mathrm{a} /$ & $=$ & $\mathrm{F}>\mathrm{T}$ & $\mathrm{F}>\mathrm{T}$ & $=$ \\
$/ \mathrm{s} /$ & $=$ & $\mathrm{F}>\mathrm{T}$ & $=$ & $=$ \\
$/ \mathrm{o} /$ & $=$ & $\mathrm{F}>\mathrm{T}$ & $\mathrm{F}<\mathrm{T}$ & $=$ \\
$/ \mathrm{u} /$ & $\mathrm{F}>\mathrm{T}$ & $\mathrm{F}>\mathrm{T}$ & $\mathrm{F}<\mathrm{T}$ & $=$ \\
\hline
\end{tabular}

- A tônica /i/ é mais baixa e mais anterior em FRASES. Os demais parâmetros não apresentam diferenças significativas. 
- A tônica/e/ é mais baixa, apresenta menor duração e maior SE em FRASES. F2 não apresenta diferença significativa.

- A tônica $/ \varepsilon /$ é mais anterior em FRASES. Os demais parâmetros não apresentam diferenças significativas.

- A tônica /a/ é mais anterior e apresenta maior duração em FRASES. Os demais parâmetros não apresentam diferenças significativas.

- A tônica / / é mais anterior em FRASES. Os demais parâmetros não apresentam diferenças significativas.

- A tônica /o/ é mais anterior e de menor duração em FRASES. Os demais parâmetros não apresentam diferenças significativas.

- A tônica /u/ é mais baixa e mais anterior e de menor duração em FRASES.

- SE só apresenta distinção na tônica /e/ (menor duração e maior SE).

- Quanto à qualidade das vogais, no que se refere à altura (F1), as vogais /i, e, u/ apresentam diferenças significativas entre estilos, tornandose ligeiramente mais altas em TEXTO.

- Na análise de F2, todas as vogais tornam-se mais posteriores em TEXTO, exceto /e/.

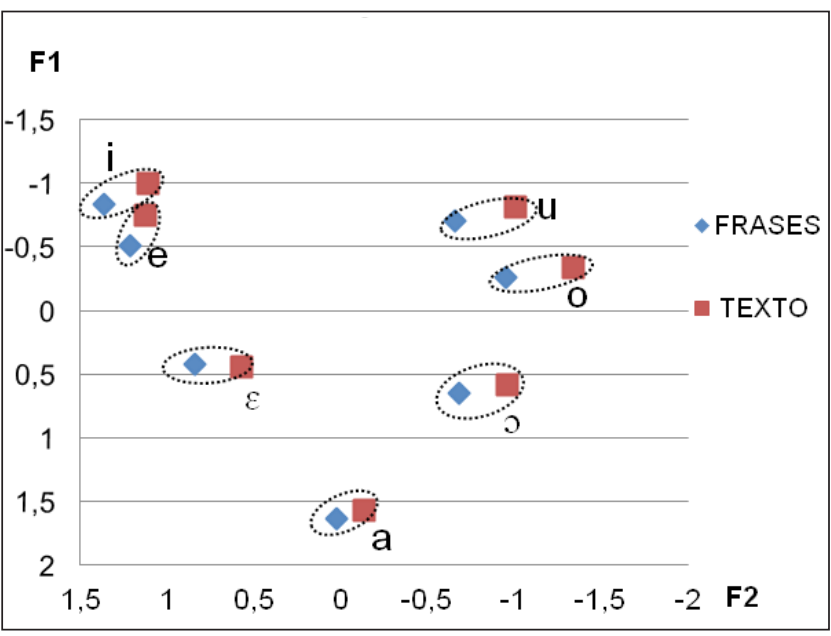

Figura 7. Tônicas - FRASES $\times$ TEXTO (F1×F2)

\section{Considerações finais}

Na comparação entre FRASES e TEXTO para as pré-tônicas de controle, /e/, /a/ e /u/ apresentam diferenças significativas entre estilos, mostrando uma tendência de tornarem-se mais altas para TEXTO, além de certa posteriorização para /a/. O parâmetro SE só apresenta distinção entre estilos para /o/, com valor mais alto em FRASES.
As pré-tônicas teste tendem a reduzir seu espaço vocálico no modo TEXTO. Além de migrarem para o centro do espaço no que se refere à altura (F1), são mais posteriores (F2) que as do modo FRASES. Em todos os casos em que ocorrem diferenças significativas para duração e SE, o estilo FRASES é o que apresenta maiores valores no que diz respeito a esses parâmetros, sendo a única exceção a pré-tônica teste /u/ diante da tônica /o/, em que SE TEXTO se apresenta maior que SE FRASE.

Todas as tônicas apresentam diferenças significativas entre estilos quanto à qualidade vocálica, de modo que i, e, u/ alteram sua altura tornando-se mais altas para TEXTO. Com exceção da tônica /e/, que não se altera, todas as outras vogais são mais posteriores em TEXTO. O parâmetro Dur é maior em FRASES para /a/ e em TEXTO para /e/, /o/ e /u/ e o parâmetro SE não apresenta diferenças significativas entre esses estilos com exceção de /e/ com valor mais alto para FRASES.

Assim, na comparação entre os estilos FRASES e TEXTO, o que se observa é um estilo mais monitorado em FRASES resultando em vogais pré-tônicas que tendem a apresentar maior duração e SE nesse estilo, além de serem mais baixas e anteriores. A tendência das vogais no modo TEXTO é a centralização e a posteriorização, resultado da hipoarticulação natural em uma fala menos atenta e mais fluente.

As diferenças encontradas entre estilos estão fortemente embasadas nas qualidades das vogais, indicadas através das análises dos parâmetros F1 e F2 e confirmadas por meio dos parâmetros duração e ênfase espectral. Esses parâmetros explicitam as marcas deixadas pelos diferentes graus de monitoramento entre estilos. Tal resultado aponta para uma direção diversa dos resultados encontrados no estudo de Barbosa, Eriksson e Ákesson (2013), que, ao compararem os estilos leitura de frases (PR) com entrevista informal (SI), não assinalaram diferenças significativas para o parâmetro $\mathrm{F} 0$ e somente o estilo leitura de palavras (WR) se manifesta distinto quando relacionado aos dois outros estilos.

Os resultados do presente estudo reiteram a proposta de W. Labov: a variação estilística está relacionada ao grau de monitoramento do falante na produção da fala. Em seus estudos sobre a cidade de Nova York, Labov (1972) demonstrou que à medida que os falantes passaram dos estilos não monitorados ("fala fora da entrevista formal", "fala com uma terceira pessoa", "fala que não responde diretamente a perguntas", "parlendas e rimas infantis" e "risco de vida") para os estilos cada vez mais formais ("situação de entrevista", estilo de leitura" e "lista de palavras"), as frequências de uso de variáveis em suas formas casuais tenderam a reduzir, entrando em seus lugares as formas mais prestigiadas. 
Assim, o presente estudo, ao avaliar a leitura de falantes capixabas, deixa claro que, de fato, diferentes graus de atenção entre os momentos de leituras de frases e de leituras de texto, resultam em vogais de qualidades mais canônicas para a situação FRASES, além de maiores durações e esforço na produção dessas vogais.

\section{Referências}

ARANTES, Pablo. Implementação em Praat de algoritmos para descrição de correlatos acústicos da prosódia da fala. In: II JORNADA DE DESCRIÇÃO DO PORTUGUÊS, II., 2011, Cuiabá. Anais da ... 2011. p. 32-38.

BARBOSA, Plínio; ERIKSSON, Anders; ÁKESSON, Joel. On the robustness of some acoustic parameters for signalling word stress across styles in brazilian portuguese. In: INTERSPEECH-2013. p. 282-286.

BELL, Allan. Back in style: reworking audience design. In: ECKERT, Penelope; RICKFORD, John R. Style and sociolinguistic variation. Cambridge University Press, 2005. p. 139-169.

BERBER SARDINHA, Tony. 2010. Corpus Brasileiro (CEPRIL, LAEL, PUCSP, FAPESP). <http://sketchengine. co.uk>.

BISOL, Leda. Introdução a estudos de fonologia do português brasileiro. 4. ed. Porto Alegre: EDIPUCRS, 2005.

CLARK, John W.; YALLOP, Collin.; FLETCHER, Janet. An introduction to phonetics and phonology. 3. ed. UK: Blackwell Publishing, 2007.

COUPLAND, Nikolas. Language, situation, and the relational self : theorizing dialect-style in sociolinguistics. In: ECKERT, Penelope; RICKFORD, John R. Style and sociolinguistic variation. Cambridge University Press, 2001. p. 185-210.
ECKERT, Penelope; RICKFORD, John R. Style and sociolinguistic variation. Cambridge University Press, 2001.

FINEGAN, Edward.; BIBER, Douglas. Register variation and dialect variation: Register Axiom. In: ECKERT, Penelope; RICKFORD, John R. Style and sociolinguistic variation. Cambridge University Press, 2001. p. 235-256.

KENT, Raymond. D.; READ, Charles. The acoustic analysis of speech. California: Singular Publishing Group, 1992.

LABOV, William. The social stratification of English in New York City. Cambridge University Press, 2006.

LABOV, William. Padrões Sociolinguísticos. São Paulo: Parábola Editorial, 2008.

LIEBERMAN, Phillip.; BLUMSTEIN, Sheila. Speech physiology, speech perception, and acoustic phonetics. Cambridge, USA: Cambridge University Press, 1988.

MIRANDA, Irma Iunes. Análise acústica das vogais orais tônicas e pré-tônicas e sua coarticulação na variedade capixaba. Tese (Doutorado em Linguística) - Instituto de Estudos da Linguagem, Universidade Estadual de Campinas, Campinas, 2017.

SLUIJTER, Agaath; Van HEUVEN, Vincent. Spectral balance as an acoustic correlate of linguistic stress. The Journal of the Acoustical society of America, v. 100, n. 4, p. 2471-2485, 1996.

TRAUNMÜLLER, Hartmut; ERIKSSON, Anders. The frequency range of the voice fundamental in the speech of male and female adults. 1995. Disponível em: <http://www2.ling. su.se/staff/hartmut/f0_m\&f.pdf >. Acesso em: 27 set. 2016.

Recebido: 30 de Setembro de 2016

Aprovado: 09 de Março de 2017

Contatos: irmaiunes@gmail.com lilianyacovenco@yahoo.com.br meirelesalex@gmail.com leilatesch@gmail.com 